\title{
Analysis of serum phosphate control and phosphate binder utilization in incident hemodialysis patients
}

This article was published in the following Dove Press journal: International Journal of Nephrology and Renovascular Disease 5 July 2014

Number of times this article has been viewed

\author{
Kimberly F Farrand \\ J Brian Copley' \\ Jamie Heise ${ }^{1}$ \\ Moshe Fridman ${ }^{2}$ \\ Michael S Keith' \\ Lynne Poole 3
}

'Shire, Wayne, PA, USA; ${ }^{2}$ AMF

Consulting, Los Angeles, CA, USA;

${ }^{3}$ Shire, Basingstoke, UK
Correspondence: Kimberly Farrand Shire, 725 Chesterbrook Blvd, Wayne, PA 19087-5637, USA

Tel +l 4845958390

Fax + I 4845958178

Email kfarrand@shire.com
Abstract: The purpose of this study was to conduct a retrospective analysis of serum phosphate level variability in patients new to hemodialysis (HD) and to identify patient characteristics associated with this variability. The medical records of 47,742 incident HD patients attending US outpatient dialysis centers between January 1, 2006 and March 31, 2009 were analyzed. Monthly mean serum phosphate levels determined over a 6-month evaluation period (months 4-9 after HD initiation) were assigned to one of three strata: low $(<1.13 \mathrm{mmol} / \mathrm{L}[<3.5 \mathrm{mg} / \mathrm{dL}])$; target $(1.13-1.78 \mathrm{mmol} / \mathrm{L}[3.5-5.5 \mathrm{mg} / \mathrm{dL}])$; or high $(>1.78 \mathrm{mmol} / \mathrm{L}[>5.5 \mathrm{mg} / \mathrm{dL}])$. Patients were classified into one of six serum phosphate variability groups based on variability among monthly mean phosphate levels over the 6-month evaluation period: consistently target; consistently high; high-to-target; high-to-low; target-to-low; or consistently low. Only 15\% of patients (consistently target group) maintained monthly mean serum phosphate levels within the target range throughout the 6-month evaluation period. Age, Charlson comorbidity index, serum phosphate, and intact parathyroid hormone levels prior to HD initiation were strongly associated $(P<0.001)$ with serum phosphate levels after HD initiation. Overall patient-reported phosphate binder usage increased from $35 \%$ at baseline to $52 \%$ at end of study. The low proportion of patients achieving target phosphate levels and low rates of phosphate binder usage observed during the study suggest that alternative strategies could be developed to control serum phosphate levels. Possible strategies that might be incorporated to help improve the management of hyperphosphatemia in incident HD patients include dietary modification, dialysis optimization, and earlier and sustained use of phosphate binders.

Keywords: chronic kidney disease, end-stage renal disease, hyperphosphatemia

\section{Introduction}

High serum phosphate levels are associated with increased mortality in patients with chronic kidney disease (CKD). ${ }^{1,2}$ In addition, hyperphosphatemia increases the risk of vascular calcification and heart disease, ${ }^{3}$ and contributes to the disruption of bone metabolism associated with renal osteodystrophy. ${ }^{3}$ In response to epidemiological data, National Kidney Foundation Disease Outcomes and Quality Initiative (K/DOQI) guidelines state that, for patients with CKD who are being treated with dialysis, serum phosphate levels should be maintained within a target range of $1.13-1.78 \mathrm{mmol} / \mathrm{L}$ (3.5-5.5 mg/dL). ${ }^{4}$ This is supported by the Kidney Disease: Improving Global Outcomes (KDIGO) guidelines, which recommend lowering phosphate levels toward the normal range $(0.8-1.4 \mathrm{mmol} / \mathrm{L}[2.5-4.5 \mathrm{mg} / \mathrm{dL}]){ }^{5}$

Serum phosphate levels in patients with CKD are managed by a combination of dietary modification, dialysis, and the use of phosphate binders. ${ }^{4}$ Dietary modification 
aims to limit the absorption of both organic and inorganic phosphate by restricting the consumption of animal proteins and processed foods rich in phosphate-containing preservatives and additives. ${ }^{5}$ Noori et $\mathrm{al}{ }^{6}$ have recommended a dietary phosphate:protein ratio of less than $10 \mathrm{mg} / \mathrm{g} /$ day for patients with CKD. However, in patients receiving hemodialysis (HD), long-term dietary phosphate restriction may induce protein energy malnutrition, ${ }^{7-10}$ which is strongly associated with increased mortality. ${ }^{11-14}$ Therefore, in addition to dietary phosphate restriction, the K/DOQI guidelines recommend that phosphate binders be used to help achieve target phosphate levels. ${ }^{4}$ The main phosphate-binding agents currently in use for patients receiving dialysis are the calcium-based compounds calcium carbonate and calcium acetate, and the calcium-free phosphate binders sevelamer hydrochloride/ carbonate and lanthanum carbonate. ${ }^{15}$

Despite measures taken to control phosphate levels in patients receiving dialysis, individual patients still have large circadian and interdialytic fluctuations in serum phosphate levels. ${ }^{16-18}$ Previous studies have assessed the association between serum phosphate levels and mortality in patients incident to HD. ${ }^{17,19-21}$ To date, however, no large-scale study has been published that assesses the variability of phosphate control on a granular monthly basis or identifies factors associated with this variability in patients new to HD. This retrospective analysis of incident HD patients was conducted in order to evaluate the degree of variability in serum phosphate levels over the 6 months of the evaluation period (months 4-9 after initiation of HD), and to assess whether baseline patient characteristics at HD initiation are associated with phosphate levels following the initiation of HD.

\section{Materials and methods}

A retrospective analysis was performed using the medical records of adult patients (age $\geq 18$ years) who received their first HD treatment, according to dialysis center data, between January 1, 2006 and March 31, 2009. National data on all dialysis patients treated by a large US dialysis provider were obtained via a licensing agreement. To be included in the study, a patient's first dialysis date was required to be no more than 30 days prior to the date of the first dialysis session with this provider (to allow for initiation of dialysis elsewhere). In addition, only patients whose dialysis sessions were recorded during the first 9 months of HD with an interruption of no more than 30 days between sessions and who had at least 4 monthly mean serum phosphate levels available during months 4 to 9 since starting HD were eligible for inclusion.
Quality control procedures to eliminate data entry errors/ outlier values were implemented. Acceptable ranges were serum phosphate $0.03-6.5 \mathrm{mmol} / \mathrm{L}(0.1-20 \mathrm{mg} / \mathrm{dL})$; intact parathyroid hormone (PTH) 0-2,000 pg/mL; equilibrated fractional clearance of body water of urea $(\mathrm{eKt} / \mathrm{V}) 0-3$; predialysis weight $30-200 \mathrm{~kg}$. Erroneous or out-of-range values were set to missing. The date of HD initiation was considered the index date. Dialysis sessions were conducted in morning, afternoon, and evening shifts; dialysis patients are typically seen during the same shift from visit to visit. Monthly serum phosphate levels were obtained per dialysis provider protocol (predialysis, mid-week, nonfasting) and were collected approximately at the same time of day for each patient.

Preindex (baseline) data were available as part of the provider's database for patient demographics (sex, race, and age) and comorbidities (myocardial infarction, congestive heart failure, peripheral vascular disease, cerebrovascular disease, chronic obstructive pulmonary disease, diabetes mellitus with and without complications, cancer, acquired immune deficiency syndrome, liver disease), and Charlson comorbidity index as well as the primary cause of CKD (urological disease, tubulointerstitial disease, cystic kidney disease, diabetes mellitus, hypertension, glomerulonephritis, or other). Baseline medications and laboratory test results were those recorded within 30 days prior to the index date, with the exception of serum phosphate and intact PTH: baseline was defined as the values closest to the index date in the period from 1 month pre- to 2 weeks postindex date; albumin: baseline was defined as the values closest to the index date in the period from 1 month pre- to 3 weeks postindex date; eKt/V: baseline was defined as the average over the first 90 days of HD; dry weight: baseline was defined as the average over the last week of the 90-day period following the index date; body surface area and body mass index (BMI): baseline values were calculated based on baseline dry weight, height, and weight; phosphate binder and vitamin D usage: baseline was defined over the first 90 days following the index date. The percentages of subjects using phosphate binders and vitamin D supplements were calculated.

Monthly mean serum phosphate levels were calculated for 6 months, from day 91 (start of month 4) to day 270 (end of month 9) of dialysis. Phosphate levels were not analyzed for the first 90 days after HD initiation due to large fluctuations expected during this period while patients become stabilized on HD. ${ }^{22}$ Monthly mean phosphate levels were assigned to one of three ranges: low $(<1.13 \mathrm{mmol} / \mathrm{L}[<3.5 \mathrm{mg} / \mathrm{dL}])$; target $(1.13-1.78 \mathrm{mmol} / \mathrm{L}[3.5-5.5 \mathrm{mg} / \mathrm{dL}])$; or high 
$(>1.78 \mathrm{mmol} / \mathrm{L}[>5.5 \mathrm{mg} / \mathrm{dL}])$. Based on the range and variability of their serum phosphate levels, patients were classified into one of six phosphate variability groups (Figure 1). The consistently target (cT), consistently high (cH), and consistently low (cL) groups comprised patients whose monthly mean phosphate levels were all in the target, high or low range, respectively. The high-to-target (HT) group described patients with at least one high reading and one target reading with no readings in the low range. Patients in the high-to-low (HL) group had at least one phosphate reading in each of the high and low ranges. The target-to-low (TL) group contained patients with at least one monthly mean phosphate reading in the target range and at least one in the low range, with no readings in the high range. Baseline patient and treatment characteristics and trends over time (using bimonthly averages over the evaluation period for months 4-5, 6-7, and 8-9 postindex date) in serum phosphate, phosphate binder usage, BMI, albumin, and $\mathrm{eKt} / \mathrm{V}$ are presented by phosphate variability groups.

Unless otherwise stated, values are expressed as mean \pm standard deviation. Overall differences between phosphate variability groups were assessed using analysis of variance for continuous variables and a chi-squared test for categorical variables. Pairwise comparisons between the cT group and the other five phosphate variability groups were tested using two-sample Student's $t$-tests for continuous variables and chi-square tests with one degree of freedom for categorical variables. To adjust for multiple comparisons, the Bonferroni correction was applied with a significance level of $a=0.01$. Analyses were performed using $\mathrm{SAS}^{\circledR}$ software version 9.1.3 (SAS Institute Inc., Cary, NC, USA).

\section{Results}

\section{Patient distribution by phosphate variability group}

A total of 87,835 patients started HD at outpatient dialysis centers between January 1, 2006 and March 31, 2009, of whom 47,742 met the inclusion criteria for the study. The main reasons for exclusion were patients receiving HD for fewer than 270 continuous days due to death $(n=14,030)$ and dialysis interruption lasting longer than 30 days $(n=25,064)$. Table 1 shows that only $15 \%(n=7,301)$ of eligible patients consistently maintained serum phosphate levels within the target range (cT group). The largest individual group was the HT group, comprising $51 \%(n=24,469)$ of patients; the smallest group was the cL group, with just $0.3 \%(n=131)$ of patients.

\section{Baseline characteristics of the phosphate variability groups}

Baseline patient and treatment characteristics by phosphate variability group are shown in Tables 1 and 2 . The cT group had a mean age of $66.6 \pm 13.7$ years, a mean serum phosphate level of $1.5 \pm 0.3 \mathrm{mmol} / \mathrm{L}(4.7 \pm 0.9 \mathrm{mg} / \mathrm{dL})$, and a mean Charlson comorbidity index of 5.6 \pm 2.1 (Figure 2A-C).

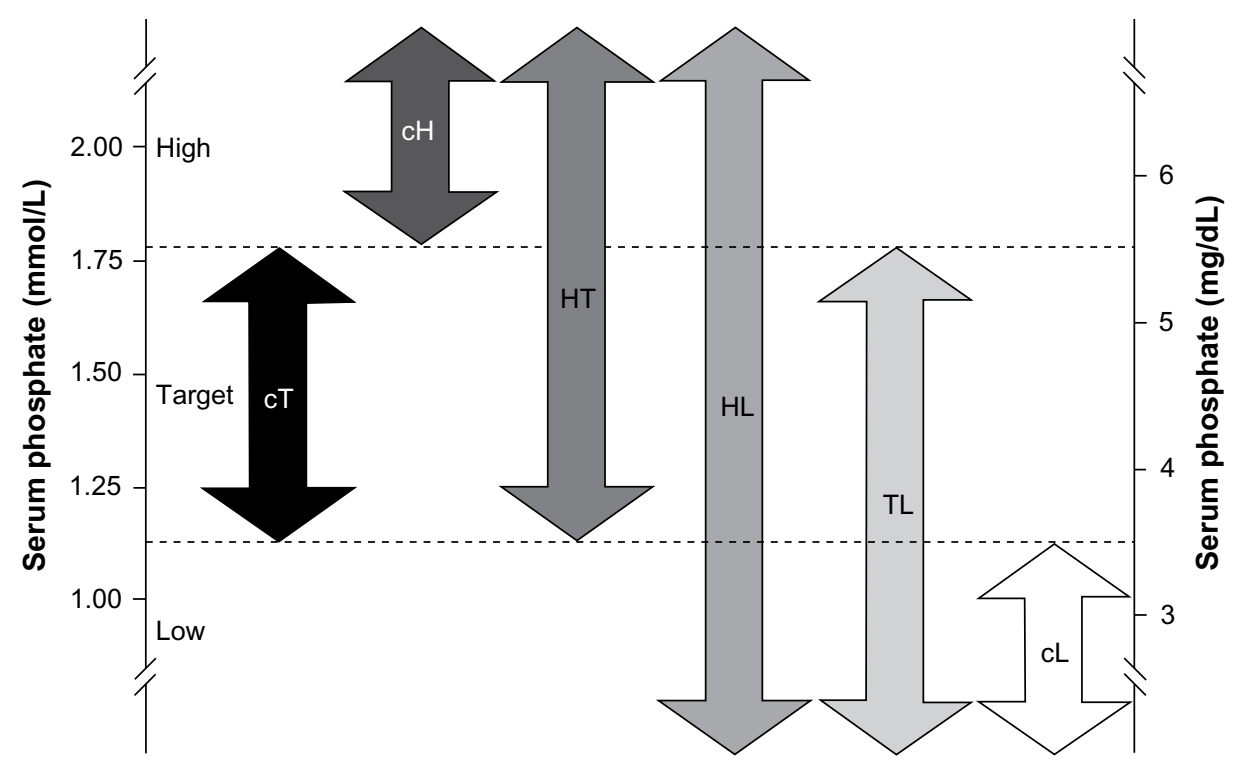

Figure I Classification of hemodialysis patients into phosphate variability groups

Note: Classification was based on the magnitude and variation of monthly mean serum phosphate levels determined over 6 months (months 4-9) following the initiation of hemodialysis.

Abbreviations: $\mathrm{cH}$, consistently high; cL, consistently low; cT, consistently target; HL, high-to-low; HT, high-to-target; TL, target-to-low. 
Table I Baseline demographic and clinical characteristics

\begin{tabular}{|c|c|c|c|c|c|c|}
\hline & \multicolumn{6}{|c|}{ Phosphate variability group } \\
\hline & cT & cH & HT & HL & TL & cL \\
\hline Patients, n (\%) & $7,30 \mathrm{I}(\mathrm{I} 5.3)$ & $5,00 I(I 0.5)$ & $24,469(5 \mid .3)$ & $4,37 \mid(9.2)$ & $6,469(13.6)$ & $131(0.3)$ \\
\hline Age, years, mean (SD) & $66.6(13.7)$ & $52.5(14.7)^{* * * *}$ & $60.6(14.7)^{* * *}$ & $63.7(14.8)^{*}$ & $68.2(13.9)^{* * *}$ & $72.1(13.0)^{* * *}$ \\
\hline Age: <65 years, $\mathrm{n}(\%)$ & $2,936(40.2)$ & $3,941(78.8)^{* * * *}$ & $|4,3| 2(58.5)^{* * *}$ & $2, \mathrm{III}(48.3)^{* * * *}$ & $2,310(35.7)^{* * * *}$ & $30(22.9) * * *$ \\
\hline Race: Caucasian, n (\%) & $3,553(48.7)$ & $2,076(4 \mid .5)^{* * *}$ & $10,599(43.4)^{* * *}$ & I,8I8 (4I.6)*** & $2,930(45.4)^{* * *}$ & $58(44.3)$ \\
\hline Sex: male, n (\%) & $4,023(55.1)$ & $3,109(62.2)^{* * *}$ & $13,662(55.8)$ & $2,339(53.5)$ & $3,7 \mid 4(57.4)^{*}$ & $82(62.6)$ \\
\hline Dry weight, kg, mean (SD) & $8 I .1(21.1)$ & $87.6(24.8)$ & $83.1(22.8)$ & $76.8(19.9)$ & $77.6(20.7)$ & $79.2(21.5)^{* * *}$ \\
\hline $\mathrm{BSA}, \mathrm{m}^{2}$, mean $(\mathrm{SD})$ & $1.9(0.3)$ & $2.0(0.3)$ & $1.9(0.3)$ & $1.8(0.3)$ & $1.9(0.3)$ & $1.9(0.3)^{* * *}$ \\
\hline BMI, kg/m², mean (SD) & $29.2(6.0)$ & $30.0(6.3)^{* * *}$ & $29.4(6.1)$ & $28.1(5.9)^{* * *}$ & $28.1(5.8)^{* * *}$ & $28.6(6.3)$ \\
\hline $\begin{array}{l}\text { Serum phosphate, } \mathrm{mmol} / \mathrm{L} \text {, } \\
\text { mean (SD) }\end{array}$ & $\mathrm{I} .5(0.3)$ & $2.3(0.5)^{* * *}$ & I.8 $(0.4)^{* * * *}$ & $1.7(0.5)^{* * *}$ & $1.4(0.3)^{* * *}$ & $1.0(0.3)^{* * *}$ \\
\hline $\begin{array}{l}\text { Serum intact PTH, } \mathrm{pg} / \mathrm{mL} \text {, } \\
\text { mean }(\mathrm{SD})\end{array}$ & $428.7(344.9)$ & $665.1(440.6)$ & $541.6(399.6)^{* * *}$ & $494.5(376.6)$ & $410.4(340.5)^{* *}$ & $373.9(302.3)^{* * *}$ \\
\hline \multicolumn{7}{|c|}{ Serum intact PTH status, $n$ (\%) } \\
\hline$\leq 600 \mathrm{pg} / \mathrm{mL}$ & $5,063(77.2)$ & $2,3 \mid 4(53.9) * * *$ & $14,230(66.0)^{* * *}$ & $2,646(69.9)^{* * *}$ & $4,596(79.3)^{*}$ & $104(86.0)$ \\
\hline$>600 \mathrm{pg} / \mathrm{mL}$ & I,495 (22.8) & $\mathrm{I}, 980(46.1)$ & $7,345(34.0)$ & $\mathrm{I}, \mathrm{I} 40(30.1)$ & $\mathrm{I}, 199(20.7)$ & $17(14.0)$ \\
\hline Albumin, g/dL, mean (SD) & $3.63(0.4 \mathrm{I})$ & $3.54(0.48)^{* * *}$ & $3.56(0.45)^{* * *}$ & $3.51(0.46)^{* * *}$ & $3.58(0.43)^{* * *}$ & $3.48(0.56)^{* * *}$ \\
\hline eKt/V, mean (SD) & $1.23(0.23)$ & $1.17(0.23)^{* * * *}$ & $1.21(0.23)^{* * *}$ & $1.23(0.22)$ & $\mathrm{I} .24(0.23)$ & $1.20(0.23)$ \\
\hline
\end{tabular}

Notes: $* P<0.01 ; * * P<0.001$; $* * * P<0.0001$ compared with the $c T$ group using two-sample Student's $t$-tests for continuous variables and chi-squared test with one $d f$ for categorical variables. Overall differences between groups were significant $(P<0.05)$ for all characteristics using the analysis of variance $(A N O V A) F$-test and chi-squared test for continuous and categorical variables, respectively. eKt $/ \mathrm{V}$ values were missing for $19.8 \%$ of the patients.

Abbreviations: BMI, body mass index (based on dry weight); BSA, body surface area (based on dry weight); cH, consistently high; cL, consistently low; cT, consistently target; $\mathrm{df}$, degree of freedom; eKt/V, equilibrated fractional clearance of body water of urea; HL, high-to-low; HT, high-to-target; PTH, parathyroid hormone; SD, standard deviation; TL, target-to-low.

Table 2 Baseline disease and medication characteristics

\begin{tabular}{|c|c|c|c|c|c|c|}
\hline & \multicolumn{6}{|c|}{ Phosphate variability group } \\
\hline & cT & $\mathbf{c H}$ & HT & HL & TL & $\mathbf{c L}$ \\
\hline Patients, n (\%) & $7,30 \mathrm{I}(\mathrm{I} 5.3)$ & $5,001(10.5)$ & $24,469(51.3)$ & $4,37 \mid(9.2)$ & $6,469(13.6)$ & $|3|(0.3)$ \\
\hline \multicolumn{7}{|l|}{ Comorbidity, n (\%) } \\
\hline MI & $7 \mid 4(9.8)$ & $340(6.8)^{* * *}$ & $2,086(8.5)^{*}$ & $382(8.7)$ & $644(10.0)$ & $13(9.9)$ \\
\hline $\mathrm{CHF}$ & $756(10.4)$ & $457(9.1)$ & $2,57 \mid(10.5)$ & $50 \mathrm{I}(1 \mathrm{I} .5)$ & 745 (I I.5) & $16(12.2)$ \\
\hline PVD & $508(7.0)$ & $26 \mid(5.2)^{* * *}$ & $1,575(6.4)$ & $288(6.6)$ & $439(6.8)$ & II (8.4) \\
\hline CVD & $117(1.6)$ & $60(1.2)$ & $332(1.4)$ & $80(1.8)$ & $145(2.2)^{*}$ & $2(1.5)$ \\
\hline COPD & $192(2.6)$ & $100(2.0)$ & $596(2.4)$ & $130(3.0)$ & $189(2.9)$ & $6(4.6)$ \\
\hline Diabetes mellitus & $3,491(47.8)$ & $2,270(45.4)^{*}$ & II,884 (48.6) & $2,084(47.7)$ & $2,920(45.1)^{*}$ & $55(42.0)$ \\
\hline Diabetes mellitus with complications & $2,254(30.9)$ & I,544 (30.9) & $7,735(31.6)$ & $1,287(29.4)$ & I,898 (29.3) & $50(38.2)$ \\
\hline Cancer & $40(0.6)$ & $14(0.3)$ & $117(0.5)$ & $31(0.7)$ & $37(0.6)$ & $2(1.5)$ \\
\hline AIDS & II (0.2) & $24(0.5)^{* *}$ & $66(0.3)$ & $22(0.5)^{* *}$ & $18(0.3)$ & $0(0.0)$ \\
\hline Charlson comorbidity index, mean (SD) & $5.6(2.1)$ & $4.3(2.0)^{* * *}$ & $5.1(2.1)^{* * *}$ & $5.3(2.2)^{* *}$ & $5.7(2.1)^{* * *}$ & $6.3(2.1)^{* * *}$ \\
\hline Number of concomitant medications, mean (SD) & $0.1(0.4)$ & $0.2(0.4)$ & $0.1(0.4)$ & $0.1(0.3)$ & $0.1(0.3)$ & $0.1(0.3)^{*}$ \\
\hline Prior transplant, $\mathrm{n}(\%)$ & $61(0.8)$ & $124(2.5)^{* * *}$ & $416(1.7)^{* * *}$ & $84(1.9)^{* * *}$ & $50(0.8)$ & $\mathrm{I}(0.8)$ \\
\hline \multicolumn{7}{|l|}{ Primary cause of CKD, $n(\%)$} \\
\hline Urological disease & $309(4.2)$ & $222(4.4)$ & $894(3.7)$ & $177(4.1)$ & $315(4.9)$ & $10(7.6)$ \\
\hline Tubulointerstitial disease & $143(2.0)$ & $102(2.0)$ & $462(1.9)$ & $97(2.2)$ & $169(2.6)$ & $4(3.1)$ \\
\hline Cystic kidney disease & $138(1.9)$ & $132(2.6)^{*}$ & $526(2.2)$ & $59(1.4)$ & $85(1.3)^{*}$ & $0(0.0)$ \\
\hline Diabetes mellitus & $3,578(49.0)$ & $2,317(46.3)^{*}$ & $12,217(49.9)$ & $1,974(45.2)^{* * *}$ & $2,800(43.3)^{* * *}$ & $54(4 \mid .2)$ \\
\hline Hypertension & $2,243(30.7)$ & I,446 (28.9) & $7,001(28.6)^{* *}$ & $1,369(31.3)$ & $2,222(34.3)^{* * *}$ & $40(30.5)$ \\
\hline Glomerulonephritis & $311(4.3)$ & $342(6.8)^{* * *}$ & $1,225(5.0)^{*}$ & $216(4.9)$ & $250(3.9)$ & $5(3.8)$ \\
\hline Other known & $296(4.1)$ & $215(4.3)$ & $1,050(4.3)$ & $253(5.8)^{* * *}$ & $315(4.9)$ & $7(5.3)$ \\
\hline Missing/unknown & $283(3.9)$ & $225(4.5)$ & $\mathrm{I}, 094(4.5)$ & $226(5.2)^{*}$ & $313(4.8)^{*}$ & $11(8.4)$ \\
\hline Patients using phosphate binders, $\mathrm{n}(\%)$ & $2,516(34.5)$ & $1,917(38.3)^{* * *}$ & $8,885(36.3)^{* *}$ & $1,399(32.0)^{* *}$ & $1,989(30.7)^{* * *}$ & $23(17.6)^{* * *}$ \\
\hline Patients using vitamin D supplements, $\mathrm{n}(\%)$ & $649(8.9)$ & $647(12.9)^{* * *}$ & $2,633(10.8)^{* * *}$ & $379(8.7)$ & $496(7.7)$ & $8(6.1)$ \\
\hline
\end{tabular}

Notes: $* P<0.01$; $* * P<0.001$; $* * * P<0.0001$ compared with the $c T$ group using two-sample Student's $t$-tests for continuous variables and chi-squared test with one $d f$ for categorical variables. Overall differences between groups were significant $(P<0.05)$ for all characteristics using the analysis of variance $(A N O V A) F$-test and chi-squared test for continuous and categorical variables, respectively.

Abbreviations: AIDS, acquired immune deficiency syndrome; $\mathrm{cH}$, consistently high; CHF, congestive heart failure; CKD, chronic kidney disease; $\mathrm{CL}$, consistently low; COPD, chronic obstructive pulmonary disease; cT, consistently target; CVD, cerebrovascular disease; HL, high-to-low; HT, high-to-target; MI, myocardial infarction; PVD, peripheral vascular disease; SD, standard deviation; TL, target-to-low; df, degree of freedom. 
A

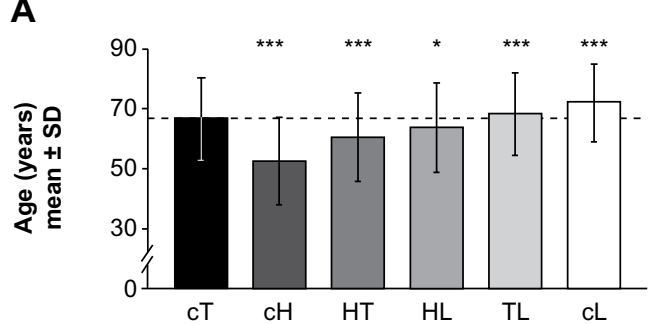

C

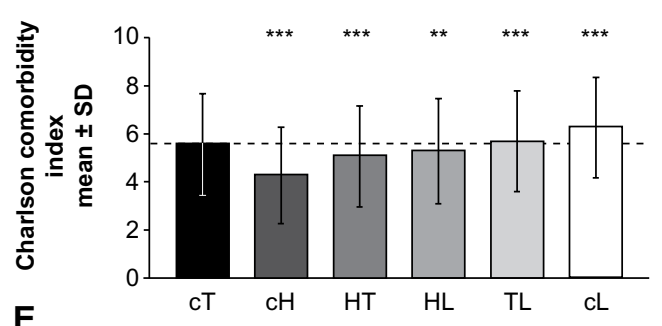

E
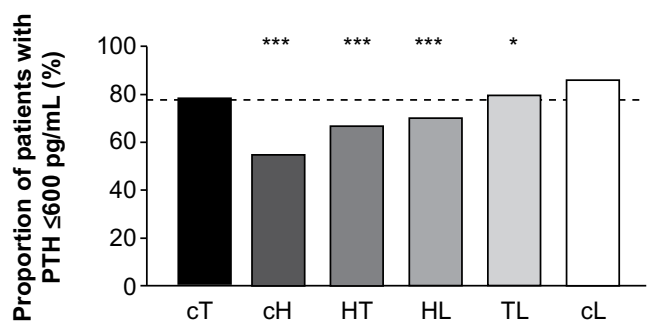

\section{B}

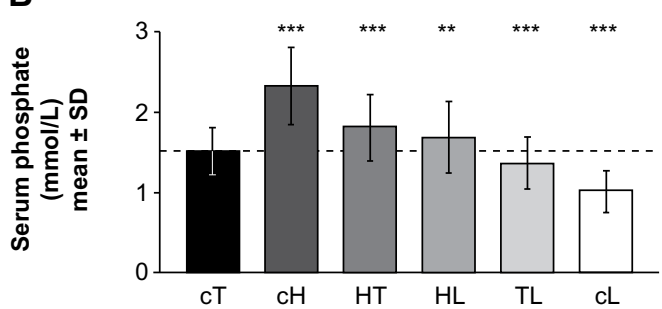

D

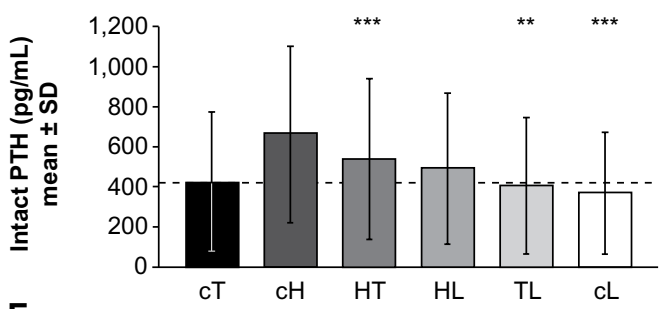

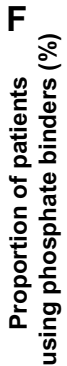

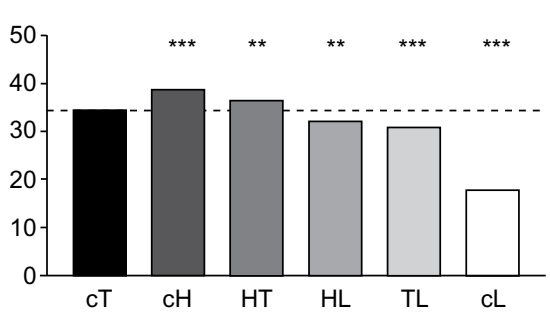

Figure 2 Baseline characteristics by phosphate variability group.

Notes: (A) mean age; (B) mean serum phosphate; (C) mean Charlson comorbidity index; (D) mean serum intact PTH; (E) proportion of patients with intact PTH $\leq 600$ pg/mL; (F) proportion of patients receiving a phosphate binder. $* P<0.01$ I; $* P<0.001$; $* * * P<0.000$ I compared with the cT group using the analysis of variance (ANOVA) $F$-test for continuous variables and the chi-squared test for categorical variables. The dashed line indicates the cT group value.

Abbreviations: $\mathrm{cH}$, consistently high; $\mathrm{cL}$, consistently low; $\mathrm{cT}$, consistently target; HL, high-to-low; HT, high-to-target; PTH, parathyroid hormone; SD, standard deviation; TL, target-to-low.

In comparison with the $\mathrm{cT}$ group, the $\mathrm{cH}$, $\mathrm{HT}$, and $\mathrm{HL}$ groups were significantly younger $(\mathrm{cH}, 52.5 \pm 14.7$ years; HT, $60.6 \pm 14.7$ years; HL, $63.7 \pm 14.8$ years), had significantly higher baseline serum phosphate levels $(\mathrm{cH}, 2.3 \pm 0.5 \mathrm{mmol} / \mathrm{L}$ $[7.2 \pm 1.5 \mathrm{mg} / \mathrm{dL}] ; \mathrm{HT}, 1.8 \pm 0.4 \mathrm{mmol} / \mathrm{L}[5.6 \pm 1.3 \mathrm{mg} / \mathrm{dL}] ; \mathrm{HL}$, $1.7 \pm 0.5 \mathrm{mmol} / \mathrm{L}[5.2 \pm 1.4 \mathrm{mg} / \mathrm{dL}])$, and a significantly lower Charlson comorbidity index (cH, $4.3 \pm 2.0$; HT, $5.1 \pm 2.1$; HL, $5.3 \pm 2.2$ ). Conversely, the TL and cL groups were significantly older than the cT group (TL, $68.2 \pm 13.9$ years; cL, $72.1 \pm 13.0$ years), had significantly lower baseline serum phosphate levels $(\mathrm{TL}, 1.4 \pm 0.3 \mathrm{mmol} / \mathrm{L}[4.2 \pm 1.0 \mathrm{mg} / \mathrm{dL}] ; \mathrm{cL}, 1.0 \pm 0.3$ $\mathrm{mmol} / \mathrm{L}[3.1 \pm 0.8 \mathrm{mg} / \mathrm{dL}])$, and a significantly higher Charlson comorbidity index (TL, 5.7 $\pm 2.1 ; \mathrm{cL}, 6.3 \pm 2.1$ ). The $\mathrm{cH}$ group had the lowest eKt/V level $(1.17 \pm 0.23)$ as well as the highest BMI $\left(30.0 \pm 6.3 \mathrm{~kg} / \mathrm{m}^{2}\right)$.

Mean intact PTH levels at baseline were higher for patients in the $\mathrm{cH}(665.1 \pm 440.6 \mathrm{pg} / \mathrm{mL}), \mathrm{HT}(541.6 \pm 399.6 \mathrm{pg} / \mathrm{mL})$, and HL $(494.5 \pm 376.6 \mathrm{pg} / \mathrm{mL})$ groups than for those in the cT group ( $428.7 \pm 344.9 \mathrm{pg} / \mathrm{mL})$; the difference was significant for the HT group (Figure 2D). Conversely, patients in the TL $(410.4 \pm 340.5 \mathrm{pg} / \mathrm{mL})$ and $\mathrm{cL}(373.9 \pm 302.3 \mathrm{pg} / \mathrm{mL})$ groups had significantly lower baseline intact PTH levels than those in the cT group. The $\mathrm{cH}(54 \%)$, HT (66\%), and HL (70\%) groups had a smaller proportion of patients with PTH levels $\leq 600 \mathrm{pg} / \mathrm{mL}$ than the cT (77\%) group (Figure 2E), whereas the TL (79\%) and cL (86\%) groups contained higher proportions of patients with intact PTH levels $\leq 600 \mathrm{pg} / \mathrm{mL}$ than the $\mathrm{cT}$ group. Baseline intact PTH levels were highly correlated with baseline phosphate levels (Pearson correlation coefficient, 0.97). Patients in the $\mathrm{cT}$ group had significantly higher mean baseline albumin levels $(3.63 \pm 0.41 \mathrm{~g} / \mathrm{dL})$ compared with all other groups $(3.48-3.58 \mathrm{~g} / \mathrm{dL})$. The proportion of patient-reported phosphate binder usage at baseline was significantly higher in the $\mathrm{cH}(38 \%)$ and HT $(36 \%)$ groups than in the cT group (35\%). Conversely, phosphate binder usage was significantly lower in the HL (32\%), TL (31\%), and cL (18\%) groups than in the cT group (Figure 2F).

\section{Trends in characteristics of the phosphate variability groups over time}

Trends in phosphate patient-reported binder usage, serum phosphate, albumin, BMI, and eKt/V over time are presented 
in Figure 3. Evaluating the study population as a whole, only $35 \%$ of patients new to HD received phosphate binder treatment at baseline (months 1-3). This increased to $52 \%$ at end of study (months 8-9), indicating that approximately half of the patients were not receiving a phosphate binder 9 months after the initiation of HD despite the majority of patients having inadequately controlled serum phosphate levels. Across the phosphate variability groups, the proportion of patients using a phosphate binder increased from baseline to end of study in all groups, except the cL group (Figure 3A). The proportion of patients on a binder in the $\mathrm{cT}$ group at end of study was $45 \%$, representing a $10 \%$ increase from baseline. The largest increases from baseline to end of study in the proportion of patients using a phosphate binder and in the percentage of days on which a binder was used were observed in the $\mathrm{cH}, \mathrm{HT}$, and HL groups. Thus, these groups contained the highest proportions of patients using phosphate binders at end of study (cH, 59\%; HT, 56\%; HL, 51\%). The lowest phosphate binder usage at end of study was seen in the cL group (16\%).

In the overall study population, mean serum phosphate levels were stable, increasing by $2.5 \%$ during the study period: baseline, $1.67 \mathrm{mmol} / \mathrm{L}(5.17 \mathrm{mg} / \mathrm{dL})$; end of study, $1.71 \mathrm{mmol} / \mathrm{L}$ $(5.30 \mathrm{mg} / \mathrm{dL})$. Within each phosphate variability group, monthly mean phosphate levels remained steady during the 6-month evaluation period (Figure 3B). Ranges of bimonthly means were: cT, $1.45-1.46 \mathrm{mmol} / \mathrm{L}(4.50-4.51 \mathrm{mg} / \mathrm{dL}) ; \mathrm{cH}$, 2.40-2.42 mmol/L (7.43-7.49 mg/dL); HT, 1.81-1.83 mmol/L (5.61-5.65 mg/dL); HL, 1.51-1.60mmol/L (4.67-4.96mg/dL); TL, $1.24-1.25 \mathrm{mmol} / \mathrm{L}(3.84-3.88 \mathrm{mg} / \mathrm{dL})$; and $\mathrm{cL}$, 0.90-0.92 mmol/L (2.77-2.84 mg/dL). Mean albumin levels increased over time in all groups from a baseline

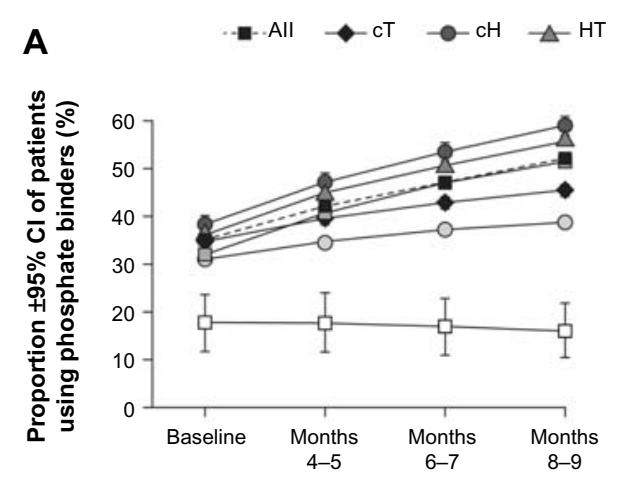

$\rightarrow-H L \quad-O-T L \quad-\square-C L$

C

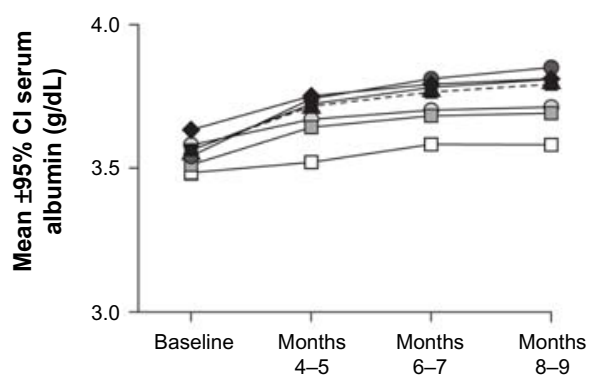

E

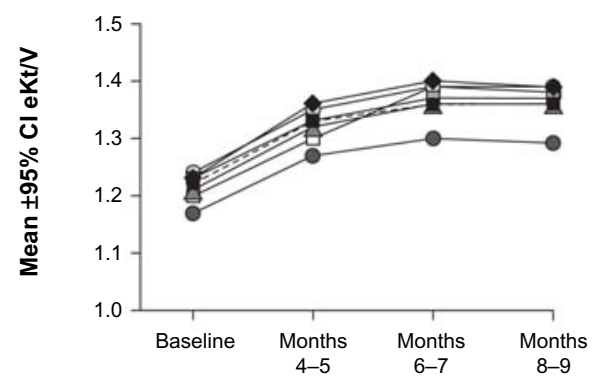

$\mathbf{B}$

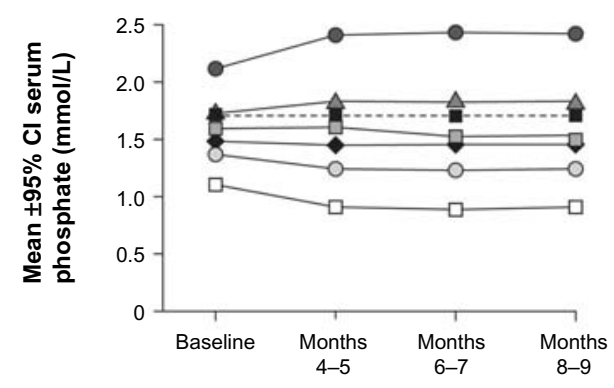

D

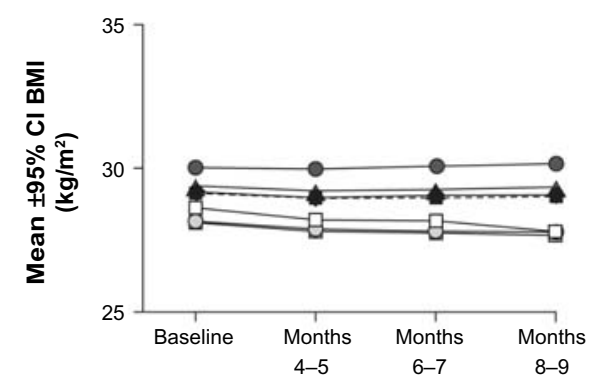

Figure 3 Trends in characteristics of the phosphate variability groups over time.

Notes: (A) proportion of patients using a phosphate binder; (B) mean serum phosphate level; (C) mean albumin; (D) mean BMI; (E) mean eKt/V. Owing to the large sample sizes, $\mathrm{Cls}$ are not visible for most data points because the bounds are very close to the means.

Abbreviations: $\mathrm{BMI}$, body mass index; $\mathrm{cH}$, consistently high; $\mathrm{Cl}$, confidence interval; $\mathrm{cL}$, consistently low; cT, consistently target; eKt/ $\mathrm{V}$, equilibrated fractional clearance of body water of urea; HL, high-to-low; HT, high-to-target; TL, target-to-low. 
of $3.5-3.6 \mathrm{~g} / \mathrm{dL}$. The highest mean albumin levels at end of study were observed in the $\mathrm{cH}$ group (3.8 $\mathrm{g} / \mathrm{dL}$ ) (Figure 3C). Mean BMI levels were consistently highest in the $\mathrm{cH}$ group, and next highest in the HT group. The lowest BMI levels were seen for the TL and HL groups (ranges of bimonthly means: TL, $27.8-27.9 \mathrm{~kg} / \mathrm{m}^{2} ; \mathrm{HL}, 27.7-27.8 \mathrm{~kg} / \mathrm{m}^{2}$ ), with a slight decreasing trend over time. Mean BMI levels in the cT group were consistent over time at approximately $29.0 \mathrm{~kg} / \mathrm{m}^{2}$ (Figure 3D). The adequacy of dialysis dose as measured by mean eKt/V improved by $0.1-0.2(8.3 \%-16.7 \%)$ from baseline to end of study across the phosphate variability groups. The lowest eKt/V levels at baseline were in the $\mathrm{cH}$ group (1.17) (Figure 3E).

\section{Discussion}

In this retrospective analysis, we examined the variability of phosphate control in 47,742 patients new to HD to determine if predialysis clinical characteristics are associated with serum phosphate levels after HD initiation. This is the first large-scale study to assess both phosphate levels and patientreported phosphate binder use throughout the 9 months following HD initiation. Only $15 \%$ of patients new to HD consistently maintained monthly mean serum phosphate levels within the K/DOQI target range. The finding that only a minority of patients were able to maintain phosphate control is in agreement with a previous study, which found that only $17 \%$ of patients remained within the target phosphate range for all four quarters of their second year on HD. ${ }^{17}$ The previous study also demonstrated lower mortality in patients who remained within the target phosphate range for the first year of HD when compared to those with serum phosphate levels outside the target range. ${ }^{17}$

Interestingly, patients in the three groups with mean baseline phosphate levels higher than those of the cT group (cH, HT, and HL groups) were significantly younger and had fewer comorbidities than those in the cT group, whereas patients in the low-phosphate groups (TL and cL groups) were older and had a greater number of comorbidities than those in the cT group. Our finding that older dialysis patients had lower serum phosphate levels than younger patients is consistent with previous studies. ${ }^{23-25}$ Older age is associated with higher levels of adherence to phosphate-binding medication, ${ }^{26}$ which may be indicative of a closely supervised health care regimen. ${ }^{27}$

An important additional factor associated with low phosphate levels in elderly patients receiving HD is a decreased appetite, leading to protein-energy malnutrition and cachexia. ${ }^{28}$ An observation within the current dataset that may support this idea is that patients in the older and hypophosphatemic cL group showed a reduction in BMI from baseline to end of study. Conversely, BMI was highest in the cH group, and next highest in the HT group. Albumin levels were also highest in the $\mathrm{cH}$ group by months $6-7$. This may be indicative of adequate or even excess protein intake, but normalized protein catabolic rate data were not available to support this contention. We found that $\mathrm{eKt} / \mathrm{V}$ was lowest in the $\mathrm{cH}$ group, and therefore these patients may have received suboptimal dialysis. At baseline, eKt/V was less than 1.2 in the $\mathrm{cH}$ group but increased with time following the initiation of dialysis. Notwithstanding, eKt/V in the $\mathrm{cH}$ group remained lower than the eKt/V of the cT group throughout the duration of the study.

Baseline intact PTH levels were strongly associated with baseline serum phosphate levels. These findings are consistent with established clinical evidence that serum phosphate levels are correlated with PTH levels in patients with CKD. ${ }^{29,30}$ In the $2003 \mathrm{~K} / \mathrm{DOQI}$ guidelines, ${ }^{4}$ the recommended target range of serum intact PTH levels for patients with stage 5 CKD is $150-300 \mathrm{pg} / \mathrm{mL}$. However, this is not supported by the available epidemiological evidence, which indicates that the inflection point above which PTH levels become significantly associated with increased all-cause mortality varies from 400 to $600 \mathrm{pg} / \mathrm{mL} .{ }^{31}$ Thus, the current consensus is for a wider PTH target range, as reflected in the 2009 KDIGO guidelines, ${ }^{5}$ which suggest a target range of $130-600 \mathrm{pg} / \mathrm{mL}$. The majority of patients new to HD in this study had mean intact PTH levels $<600 \mathrm{pg} / \mathrm{mL}$.

In the overall study population, approximately half $(52 \%)$ of the patients were using phosphate binders at end of study. This is in contrast to a binder-usage rate of $88 \%$ that was recently reported in the Dialysis Outcomes and Practice Patterns Study (DOPPS). ${ }^{32}$ The disparity in phosphate binder usage between the current study and DOPPS may be explained by noting that our data on binder usage were patient-reported and the patients in the current study were all new to HD, whereas in the DOPPS study, the mean duration of end-stage renal disease was 3.4 years, and that binder usage would be expected to increase over time. Indeed, following the initiation of HD in this study, phosphate binder usage increased in all groups except the cL group. The largest increases in binder usage occurred in the $\mathrm{cH}$, HT, and HL groups, containing patients with the highest phosphate levels. However, the proportion of patients using phosphate binders in these groups was still relatively low (51\%-59\%), which may explain why phosphate levels remained high in these groups. 
A limitation of the analysis is that data on type, dosage, and adherence to phosphate binder medication were not available. Our binder usage data are based on patient-reported information that may not be accurate or complete. Poor adherence to phosphate binders is known to be prevalent in patients with end-stage renal disease. ${ }^{26,27}$ Additionally, data presented are "real-world", therefore phosphate binder titration protocols to specific targets were not rigidly enforced, as is the case in "treat-to-target" prospective clinical trials. As the only patients included were those who survived the first year of HD and had no interruption of dialysis in-clinic treatment for more than 90 days, results should not be generalized to a sicker patient population. In addition, the usual potential biases associated with retrospective data analysis apply to our results, including possible selection bias and variation in reporting standards and accuracy. However, given the large national sample used, we believe the results are representative of real-world practice.

The large proportion of incident HD patients with at least one high monthly mean serum phosphate level suggests that developing alternative strategies to control serum phosphate are needed. Such strategies may include the combination of dietary modification, adequate dialysis, and administration of phosphate binders to hyperphosphatemic patients upon initiation of HD to improve early phosphate control. With regard to binder usage in the early stage of $\mathrm{HD}$, the use of phosphate binders during the first 90 days after initiation of HD has been shown to be associated with a reduction in mortality in HD patients. ${ }^{19}$ Further studies are required to evaluate the utility of early, aggressive administration of phosphate binders for the management of hyperphosphatemia in patients with end-stage renal disease requiring HD.

In this retrospective analysis of patients new to $\mathrm{HD}$, only $15 \%$ of patients maintained serum phosphate levels consistently within the K/DOQI target range, indicating that phosphate control is difficult to achieve in this patient population. Despite the majority of patients having higher-than-target monthly mean levels of serum phosphate for at least 1 month during the study, rates of phosphate binder usage were lower than those reported in previous studies. It is conceivable that earlier and sustained administration of phosphate binders to incident HD patients with attention to patient nutritional status and dialysis adequacy could help improve the management of serum phosphate levels in these patients.

\section{Acknowledgments}

Writing and editorial support was provided by Fernando Gibson and Rosalind Morley, employees of PharmaGenesis ${ }^{\text {TM }}$
London, with funding from Shire Development LLC. Arthur Silverberg, an employee of Shire, provided statistical expertise.

\section{Disclosure}

Kimberly Farrand, J Brian Copley, Jamie Heise, Michael Keith, and Lynne Poole are employees of Shire. Moshe Fridman is a consultant to Shire. The results presented in this manuscript are derived from analysis of dialysis center data, obtained via a data licensing agreement. The analysis was funded by Shire Development LLC. The authors declare that the results presented in this paper have not been published previously in whole or part, except in abstract format. The authors report no other conflicts of interest in this work.

\section{References}

1. Block GA, Klassen PS, Lazarus JM, Ofsthun N, Lowrie EG, Chertow GM. Mineral metabolism, mortality, and morbidity in maintenance hemodialysis. J Am Soc Nephrol. 2004;15(8):2208-2218.

2. Kestenbaum B, Sampson JN, Rudser KD, et al. Serum phosphate levels and mortality risk among people with chronic kidney disease. J Am Soc Nephrol. 2005;16(2):520-528.

3. Cannata-Andia JB, Roman-Garcia P, Hruska K. The connections between vascular calcification and bone health. Nephrol Dial Transplant. 2011;26(11):3429-3436.

4. National Kidney Foundation. K/DOQI clinical practice guidelines for bone metabolism and disease in chronic kidney disease. Am J Kidney Dis. 2003;42(4 Suppl 3):S1-S201.

5. Kidney Disease: Improving Global Outcomes (KDIGO) CKD-MBD Work Group. KDIGO clinical practice guideline for the diagnosis, evaluation, prevention, and treatment of chronic kidney disease-mineral and bone disorder (CKD-MBD). Kidney Int Suppl. 2009;(113):S1-S130.

6. Noori N, Sims JJ, Kopple JD, et al. Organic and inorganic dietary phosphorus and its management in chronic kidney disease. Iran J Kidney Dis. 2010;4(2):89-100.

7. Coladonato JA. Control of hyperphosphatemia among patients with ESRD. J Am Soc Nephrol. 2005;16(Suppl 2):S107-S114.

8. Ikizler TA. Dietary protein restriction in CKD: the debate continues. Am J Kidney Dis. 2009;53(2):189-191.

9. Rufino M, de Bonis E, Martín M, et al. Is it possible to control hyperphosphataemia with diet, without inducing protein malnutrition? Nephrol Dial Transplant. 1998;13(Suppl 3):65-67.

10. Shinaberger CS, Greenland S, Kopple JD, et al. Is controlling phosphorus by decreasing dietary protein intake beneficial or harmful in persons with chronic kidney disease? Am J Clin Nutr. 2008;88(6):1511-1518.

11. Kalantar-Zadeh K, Supasyndh O, Lehn RS, McAllister CJ, Kopple JD. Normalized protein nitrogen appearance is correlated with hospitalization and mortality in hemodialysis patients with $\mathrm{Kt} / \mathrm{V}$ greater than 1.20. J Ren Nutr. 2003;13(1):15-25.

12. Lacson E, Ikizler TA, Lazarus JM, Teng M, Hakim RM. Potential impact of nutritional intervention on end-stage renal disease hospitalization, death, and treatment costs. J Ren Nutr. 2007;17(6):363-371.

13. Pupim LB, Caglar K, Hakim RM, Shyr Y, Ikizler TA. Uremic malnutrition is a predictor of death independent of inflammatory status. Kidney Int. 2004;66(5):2054-2060.

14. Rambod M, Bross R, Zitterkoph J, et al. Association of MalnutritionInflammation Score with quality of life and mortality in hemodialysis patients: a 5-year prospective cohort study. Am J Kidney Dis. 2009; 53(2):298-309. 
15. Collins AJ, Foley RN, Chavers B, et al. 'United States Renal Data System 2011 Annual Data Report: Atlas of chronic kidney disease and end-stage renal disease in the United States. Am J Kidney Dis. 2012; 59(1 Suppl 1):A7, e1-e420.

16. Becker GJ, Walker RG, Hewitson TD, Pedagogos E. Phosphate levels time for a rethink? Nephrol Dial Transplant. 2009;24(8):2321-2324.

17. Danese MD, Belozeroff V, Smirnakis K, Rothman KJ. Consistent control of mineral and bone disorder in incident hemodialysis patients. Clin J Am Soc Nephrol. 2008;3(5):1423-1429.

18. Ring T, Sanden AK, Hansen HH, Halkier P, Nielsen C, Fog L. Ultradian variation in serum phosphate concentration in patients on haemodialysis. Nephrol Dial Transplant. 1995;10(1):59-63.

19. Isakova T, Gutiérrez OM, Chang Y, et al. Phosphorus binders and survival on hemodialysis. J Am Soc Nephrol. 2009;20(2):388-396.

20. Gutiérrez OM, Mannstadt M, Isakova T, et al. Fibroblast growth factor 23 and mortality among patients undergoing hemodialysis. N Engl J Med. 2008;359(6):584-592.

21. Melamed ML, Eustace JA, Plantinga L, et al. Changes in serum calcium, phosphate, and PTH and the risk of death in incident dialysis patients a longitudinal study. Kidney Int. 2006;70(2):351-357.

22. Selvarajah V, Pasea L, Ojha S, Wilkinson IB, Tomlinson LA. Pre-dialysis systolic blood pressure-variability is independently associated with all-cause mortality in incident haemodialysis patients. PLoS One. 2014;9(1):e86514.

23. Pelletier S, Roth H, Bouchet JL, Drueke T, London G, Fouque D; French Phosphorus and Calcium Observatory investigators. Mineral and bone disease pattern in elderly haemodialysis patients. Nephrol Dial Transplant. 2010;25(9):3062-3070.

24. Yavuz A, Ersoy FF, Passadakis PS, et al. Phosphorus control in peritoneal dialysis patients. Kidney Int Suppl. 2008;(108):S152-S158.
25. Young EW, Albert JM, Satayathum S, et al. Predictors and consequences of altered mineral metabolism: the Dialysis Outcomes and Practice Patterns Study. Kidney Int. 2005;67(3):1179-1187.

26. Karamanidou C, Clatworthy J, Weinman J, Horne R. A systematic review of the prevalence and determinants of nonadherence to phosphate binding medication in patients with end-stage renal disease. $B M C$ Nephrol. 2008;9:2.

27. Arenas MD, Malek T, Gil MT, Moledous A, Alvarez-Ude F, Reig-Ferrer A. Challenge of phosphorus control in hemodialysis patients: a problem of adherence? J Nephrol. 2010;23(5):525-534.

28. Lecker SH. Given the science on malnutrition, how does the clinician respond? Practical lessons for and application to the dialysis patient. Clin J Am Soc Nephrol. 2009;4(Suppl 1):S64-S70.

29. Pires A, Adragão T, Pais MJ, Vinhas J, Ferreira HG. Inferring disease mechanisms from epidemiological data in chronic kidney disease: calcium and phosphorus metabolism. Nephron Clin Pract. 2009;112(3): c137-c147.

30. Slatopolsky E, Brown A, Dusso A. Role of phosphorus in the pathogenesis of secondary hyperparathyroidism. Am J Kidney Dis. 2001 37(1 Suppl 2):S54-S57.

31. Uhlig K, Berns JS, Kestenbaum B, et al. KDOQI US commentary on the 2009 KDIGO Clinical Practice Guideline for the Diagnosis, Evaluation, and Treatment of CKD-Mineral and Bone Disorder (CKD-MBD). Am J Kidney Dis. 2010;55(5):773-799.

32. Lopes AA, Tong L, Thumma J, et al. Phosphate binder use and mortality among hemodialysis patients in the Dialysis Outcomes and Practice Patterns Study (DOPPS): evaluation of possible confounding by nutritional status. Am J Kidney Dis. 2012;60(1):90-101.

\section{Publish your work in this journal}

The International Journal of Nephrology and Renovascular Disease is an international, peer-reviewed open-access journal focusing on the pathophysiology of the kidney and vascular supply. Epidemiology, screening, diagnosis, and treatment interventions are covered as well as basic science, biochemical and immunological studies. The journal welcomes

\section{Dovepress}

original research, clinical studies, reviews \& evaluations, expert opinion and commentary, case reports and extended reports. The manuscript management system is completely online and includes a very quick and fair peerreview system, which is all easy to use. Visit http://www.dovepress.com/ testimonials.php to read real quotes from published authors. 